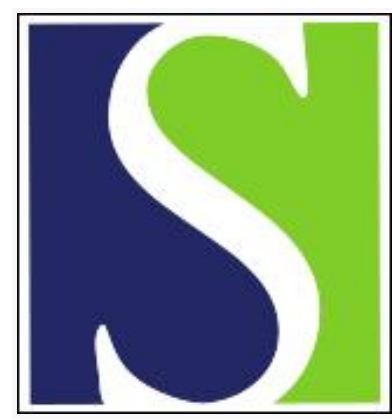

Scand J Work Environ Health 2012;38(3):247-258

https://doi.org/10.5271/sjweh.3188

Published online: 17 Aug 2011, Issue date: May 2012

Sensitization and chronic beryllium disease at a primary manufacturing facility, part 1: historical exposure reconstruction

by Virji MA, Park JY, Stefaniak AB, Stanton ML, Day GA, Kent MS, Kreiss $\mathrm{K}$, Schuler CR

Affiliation: National Institute for Occupational Safety and Health, Centers for Disease Control and Prevention, Mailstop H-2800, Morgantown, WV 26505. MVirji@cdc.gov

Refers to the following text of the Journal: 2012;38(3):259-269

The following articles refer to this text: 2012;38(3):259-269; 2012;38(3):270-281

Key terms: average exposure; beryllium; chronic beryllium disease; cumulative exposure; exposure; exposure reconstruction; historical exposure; historical exposure reconstruction; manufacturing; peak exposure; respirable exposure; sensitization; submicron exposure; total exposure

This article in PubMed: www.ncbi.nlm.nih.gov/pubmed/21850365

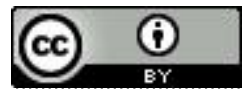




\title{
Sensitization and chronic beryllium disease at a primary manufacturing facility, part 1: historical exposure reconstruction
}

\author{
By M Abbas Virji, ScD, ${ }^{1}$ Ji Young Park, PhD, ${ }^{1}$ Aleksandr B Stefaniak, PhD, ${ }^{1}$ Marcia L Stanton, BS, ${ }^{1}$ \\ Gregory A Day, PhD, ${ }^{1}$ Michael S Kent, MS, ${ }^{1}$ Kathleen Kreiss, MD, ${ }^{1}$ Christine R Schuler, PhD ${ }^{1}$
}

\begin{abstract}
Virji MA, Park JY, Stefaniak AS, Stanton ML, Day GA, Kent MS, Kreiss K, Schuler CR. Sensitization and chronic beryllium disease at a primary manufacturing facility, part 1: historical exposure reconstruction. Scand J Work Environ Health. 2012;38(3):247-258. doi:10.5271/sjweh.3188
\end{abstract}

Objectives Previous epidemiologic studies of beryllium sensitization (BeS) and chronic beryllium disease (CBD) have reported inconsistent exposure-response relationships, likely due to exposure misclassification. The objective of this study was to develop historical estimates of size-selective personal exposure to beryllium for an epidemiologic study.

Methods In 1999, a cross-sectional survey of workers hired after 1 January 1994 was conducted at a beryllium production facility. Personal exposure data from two air sampling surveys conducted in 1999 were used to obtain total, respirable, and submicron particle baseline exposure estimates (BEE) for a job-exposure matrix (JEM). General area air samples collected from 1994-1999 were used to estimate annual changes in exposures (temporal factors) for 24 different process areas. Historical exposure estimates (HEE) were calculated by applying the temporal factors to the BEE. Workers were assigned HEE based on their work history, and their historical exposure profile was summarized as cumulative, average, or highest-ever job exposure.

Results Changes in exposure over a 6-year period were observed in 10 of the 24 process areas with an overall mean decline of $18 \%$ per year. The overall total exposure for study participants over their work tenure ranged from: $0.001-34.44 \mu \mathrm{g} / \mathrm{m}^{3}$-year, $0.01-16.26 \mu \mathrm{g} / \mathrm{m}^{3}$, and $0.01-17.54 \mu \mathrm{g} / \mathrm{m}^{3}$ for cumulative, average, and highestever job, respectively. For respirable exposures, the ranges were: $0.001-15.54 \mu \mathrm{g} / \mathrm{m}^{3}$-year, $0.01-3.56 \mu \mathrm{g} / \mathrm{m}^{3}$, $0.01-5.54 \mu \mathrm{g} / \mathrm{m}^{3}$ for cumulative, average, and highest-ever job, respectively.

Conclusions Using this JEM, exposure-response relationships for $\mathrm{BeS}$ and $\mathrm{CBD}$ can be explored over a range of exposure metrics such as total, respirable, and submicron beryllium mass concentrations, including summary measures such as cumulative, average, or highest exposures, with the ultimate objective of elucidating a quantitative exposure-response relationship.

Key terms average exposure; cumulative exposure; peak exposure; respirable exposure; submicron exposure; total exposure.

Epidemiologic studies conducted since the early 1990s have often reported elevated prevalences of beryllium sensitization (BeS) and chronic beryllium disease (CBD) associated with specific work processes; however exposure-response relationships have been inconsistent $(1,2)$. The presence of process-specific health risk suggests that predictive exposure factors exist but may not have been adequately characterized. For example, some studies of BeS and CBD are based on exposure surrogates such as work process or job title due to a lack of exposure data. Seven studies have utilized quantitative exposure data, most often the daily weighted average exposure, a combination of the breathing zone task and general area air samples with task/activity-time data. In the primary beryllium production industry, Kreiss et al (3) and Rosenman et al (4) used daily weighted average, breathing zone, or general area beryllium exposure estimates, and neither study observed exposure-response relationships for $\mathrm{BeS}$ or $\mathrm{CBD}$. In primary production, both particle size

\footnotetext{
${ }^{1}$ National Institute for Occupational Safety and Health (NIOSH), Division of Respiratory Disease Studies, Morgantown, WV, USA.

${ }^{2}$ Materion Brush Inc, Elmore, OH, USA.
}

Disclaimer: Mention of a specific product or company does not constitute endorsement by the Centers for Disease Control and Prevention. The findings and conclusions in this report are those of the authors and do not necessarily represent the views of NIOSH.

Correspondence to: M Abbas Virji, National Institute for Occupational Safety and Health, Centers for Disease Control and Prevention, Mailstop H-2800, Morgantown, WV 26505. [E-mail: MVirji@cdc.gov] 
distribution and beryllium solubility are known to vary among processes $(5,6)$. Two studies were conducted in the ceramics industry using the daily weighted average, breathing zone, or general area beryllium exposure estimates $(7,8)$. Both studies reported weak exposureresponse relationships for $\mathrm{BeS}$ and $\mathrm{CBD}$; aerosols in the ceramics industry are reported to be in the respirable size range (7) and are poorly soluble in the lung (9). In the nuclear industry, Stange et al (10) and Viet et al (11) used fixed air head samples (area exposure data from one building) in combination with professional judgment of exposure factors to estimate exposures for jobs in multiple buildings. Stange et al (10) did not observe an exposure-response relationship in their longitudinal analysis, while Viet et al's case-control study (11) reported an exposure-response relationship. Finally, Kelleher et al's study (12) surveyed a beryllium machining facility using size-selective exposure estimates obtained from impactor samples. The study reported consistent exposure-response relationships for $\mathrm{BeS}$ and $\mathrm{CBD}$ with beryllium particles $<1 \mu \mathrm{m},<6 \mu \mathrm{m}$ and total beryllium, albeit non-significant.

The size distribution and solubility of beryllium particles deposited in the respiratory tract are important factors that determine the course of action of these particles, and may be important to understanding processrelated risk (2). Thus, factors precluding the identification of an exposure-response relationships in previous studies may include: lack of biological relevance of exposure indices and summary measures; lack of accurate and precise estimates of historical exposure; lack of knowledge of time between first exposure and onset of $\mathrm{BeS}$ or CBD; different bioavailability among forms of beryllium; exclusion of the skin as a route of exposure and sensitization; and lack of consideration of the impact of dose rate and genetic susceptibility.

The overall objective of this project was to develop biologically relevant exposure metrics for use in epidemiologic studies of BeS and CBD. In this study, the focus was on generating estimates of historical exposure to submicron $(<1 \mu \mathrm{m})$, respirable, and total beryllium for use in the epidemiologic study of short-term workers ( $\leq 6$ years work tenure) at a primary beryllium production facility.

\section{Methods}

A cross-sectional survey for BeS and CBD was conducted in 1999 at a beryllium production facility, and a sub-cohort of 264 short-term workers was defined by date of hire after 1 January 1994. Survey instruments included: medical and work-history questionnaires, blood samples to test for BeS, and clinical evaluation of sensitized workers for $\mathrm{CBD}$; these are reported in detail in the companion paper (13). Historical beryllium exposures were reconstructed for the short-term workers using a job-exposure matrix (JEM) and work history information from their date of hire to either (i) their date of diagnosis or (ii) the date of the survey in 1999.

\section{The facility}

The facility at which the study was conducted is a large and complex primary beryllium manufacturing plant that produces the following: soluble beryllium compounds; beryllium metal powder, billet, rod, sheet, and pressed and machined shapes; beryllium oxide powder; and beryllium-containing alloys, mostly as copper-beryllium billets, rods, wire and strip products. Details of the manufacturing processes and jobs have been summarized previously (5). The processes and jobs at this facility are characterized by variable forms of beryllium, beryllium exposure levels, particle size distribution, and solubility in biological fluids.

\section{Data sources}

The data for this study were obtained from the company from two sources: targeted sampling campaigns and ongoing surveillance monitoring. The company conducted process surveillance monitoring by collecting general area air samples from most areas of the plant, but with a special focus on areas and processes with known high beryllium exposures (14). The general area data $(\mathrm{N}=76349$ for the years 1994-1999) were collected from 274 fixed locations within the 24 process areas (identified in table 1) across all production and selected non-production units. General area air samples were collected using three sampling methods including: high volume (200-400 Lpm), continuous (10-20 Lpm), and low-flow (2 Lpm) sampling methods (14). While information on sampling methods was not available, sampling durations of the general area samples included: $1-5$ days $(4.5 \%), 10-24$ hours $(10 \%), 6-10$ hours $(76 \%),<6$ hours $(9.5 \%)$. The general area air sample database provided to the National Institute for Occupational Safety and Health (NIOSH) did not include information that identified measurements below the limit of detection (LOD). Examination of the database showed the lowest concentration recorded was $0.1 \mu \mathrm{g} / \mathrm{m}^{3}$, which corresponded to the previously reported LOD concentration (14). Thus all measurements with a beryllium concentration of $0.1 \mu \mathrm{g} / \mathrm{m}^{3}$ were noted as LOD samples. The general area data were utilized in evaluating time trends in beryllium air levels.

Two targeted sampling campaigns were conducted over 2-3 months in 1999 that collected size-separated personal impactor samples from 76 representative jobs ( $\mathrm{N}=198$ samples) and personal 37-mm closed-face 
cassette (CFC) "total" samples from 269 jobs $(\mathrm{N}=4022$ samples) that represented most jobs at the facility (5). The air sampling campaigns coincided with the health assessment survey for BeS and CBD and formed the basis for estimating the baseline exposures of the study participants. Details of the sampling and analysis methods have been described previously and are briefly summarized below (5). The impactor samples were configured to use only 5 of the 8 stages starting with stage 4 which provided a $50 \%$ aerodynamic cutoff diameter $\left(D_{50}\right)$ of $6.0 \mu \mathrm{m}$. Personal full-shift (6-10 hours) and multi-shift ( $2-5$ shifts to minimize LOD issues) impactor samples were collected from workers at a sampling flow rate of 2 Lpm. For the CFC survey, repeated (2-17 measurements) personal samples were collected from workers for a fullshift ( $>6$ hours) using air sampling pumps calibrated at 2 Lpm. The LOD for the impactor and CFC total samples were 0.003 and $0.02 \mu \mathrm{g} /$ filter, respectively. All data were provided to NIOSH for the generation of a JEM and the creation of personal exposure estimates for the study population.

\section{Exposure reconstruction}

Exposure reconstruction was conducted for jobs in the short-term workers population to generate a JEM that spanned from 1994-1999. The historical general area air sampling data were used to calculate the annual changes in air levels for the years 1994-1998 compared to the baseline year of 1999 (temporal factors) for the different process areas. Historical exposure estimates (HEE) were calculated by applying the temporal factors to the baseline exposure estimates (BEE) for each job to generate the JEM. The HEE were applied to each worker's work history to generate worker-specific historical exposure profiles, which were then summarized and used in epidemiologic analyses (figure 1).

Time trend analysis. The trends in exposure over time were evaluated using the general area data in regression models to estimate the overall and process-specific annual change in exposure for the years 1994-1998, compared to the baseline year of 1999. A large fraction of the general area data were below the LOD in the different process areas (table 1), thus the temporal factors for the years by process areas $\left(T F_{p a, y}\right)$ were estimated using Tobit regression models (15). Tobit regression uses the maximum likelihood estimate (MLE) method to provide estimates of the temporal factors while accounting for the measurement data below the LOD. The loglikelihood function used in Tobit regression has two components, one for observed data and the other for data below the LOD; MLE of the model parameters (eg, $\beta_{\text {process area, year }}$ ) are then obtained by maximizing the log likelihood function (15). The parameter estimates from
Table 1. General area air samples from the 24 process areas.

\begin{tabular}{|c|c|c|c|}
\hline Process area & N & $\begin{array}{l}\text { LOD } \\
(\%)^{\text {a }}\end{array}$ & Description \\
\hline \multicolumn{4}{|l|}{ Beryllium metal } \\
\hline Wet plant & 10405 & $22-66$ & $\begin{array}{l}\text { Wet chemical processing and drying, } \\
\text { and solution preparation for beryllium } \\
\text { recovery }\end{array}$ \\
\hline Pebbles & 13478 & $19-46$ & $\begin{array}{l}\text { Production of beryllium pebbles e.g. } \\
\text { fluoride/reduction furnaces and ham- } \\
\text { mer mills }\end{array}$ \\
\hline All PMP & 7207 & $48-87$ & $\begin{array}{l}\text { Processes for manufacturing beryllium } \\
\text { powder metal products (PMP) except } \\
\text { atomizer }\end{array}$ \\
\hline Atomizer & 2206 & $20-34$ & $\begin{array}{l}\text { Atomizer area separate from the rest } \\
\text { of the PMP }\end{array}$ \\
\hline Machining & 1730 & $72-90$ & Beryllium metal machining \\
\hline \multicolumn{4}{|l|}{ Beryllium oxide } \\
\hline & 4321 & $10-43$ & $\begin{array}{l}\text { Beryllium oxide manufacturing and } \\
\text { screening }\end{array}$ \\
\hline \multicolumn{4}{|l|}{ Beryllium alloy } \\
\hline Whiting & 7898 & $25-64$ & Preparation of beryllium master alloy \\
\hline OCS/BP & 12853 & $10-30$ & $\begin{array}{l}\text { Casting and billet preparation (old } \\
\text { cast shop) }\end{array}$ \\
\hline NCS & 2596 & $52-71$ & $\begin{array}{l}\text { Casting and billet preparation (new } \\
\text { cast shop) }\end{array}$ \\
\hline $\begin{array}{l}\text { Scrap } \\
\text { furnace }\end{array}$ & 7094 & 28 & Scrap furnaces \\
\hline Extrusion & 107 & $63-78$ & Roun \\
\hline RBT & 11 & $33-100$ & Rod, \\
\hline Old Strip & 986 & $32-59$ & Strip milling at old building \\
\hline NSM & 257 & $71-82$ & Strip milling at new strip milling \\
\hline LGSM & 11 & $67-100$ & Light gauge strip milling \\
\hline \multicolumn{4}{|c|}{ Miscellaneous production } \\
\hline $\begin{array}{l}\text { Resource } \\
\text { Recovery }\end{array}$ & 1018 & $14-100$ & Electro-winning and resource recovery \\
\hline QA/QC \& RD & 870 & 100 & $\begin{array}{l}\text { Quality assurance/control and research } \\
\text { and development areas }\end{array}$ \\
\hline \multicolumn{4}{|c|}{ Non-production area } \\
\hline $\begin{array}{l}\text { Admin } \\
\text { (office) }\end{array}$ & 70 & $75-100$ & Administrative - office areas \\
\hline $\begin{array}{l}\text { Admin } \\
\text { (plant) }\end{array}$ & 41 & $40-100$ & $\begin{array}{l}\text { Administrative - office areas in the } \\
\text { plant }\end{array}$ \\
\hline Maintenance & 2924 & $85-97$ & Maintenance building \\
\hline $\begin{array}{l}\text { Waste } \\
\text { treatment }\end{array}$ & 11 & 100 & $\begin{array}{l}\text { Waste and industrial waste water } \\
\text { treatment }\end{array}$ \\
\hline $\begin{array}{l}\text { Shipping \& } \\
\text { receiving }\end{array}$ & 59 & $45-67$ & $\begin{array}{l}\text { Shipping and receiving beryllium } \\
\text { product or raw material }\end{array}$ \\
\hline Laundry & 22 & $60-100$ & Laundry and respirator cleaning areas \\
\hline Janitorial & 47 & $53-100$ & Locker rooms and change facilities \\
\hline
\end{tabular}

${ }^{a}$ Range of percent of samples below the limit of detection (LOD) for the different years between 1994-1999.

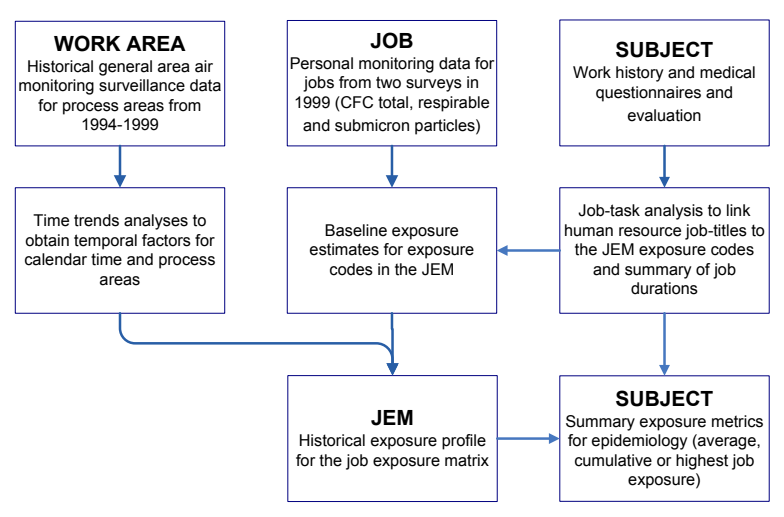

Figure 1. Overview of the historical exposure reconstruction approach. 
the Tobit model, $T F_{p a, y}$ formed the basis for the historical exposure reconstruction. When the parameter estimates for the different years were not significantly different from one another, the years were combined (grouped time periods) to reflect periods during which exposures remained relatively constant. The regression model was re-run with the grouped years as the independent variable instead of the single year.

Identification of jobs in the work histories for the JEM. Work history questionnaires were administered by trained occupational health nurses from the company, using personnel records as a memory aid for job titles and dates. Study participants reported their job title, start and end dates, and the average number of days worked per week for all the jobs held at the facility. The work histories were summarized to identify all the job titles held by the workers in the cohort. However, the job titles in the work histories were assigned by human resources (hereafter referred to as HR job title) and were generic. Often the same HR job title was applied to workers in different process areas of the plant with potentially different exposures. For example, the HR job title "machinists" could be located in different areas of the plant machining either beryllium alloy, pure beryllium metal products, or non-beryllium machine parts. To further clarify the location and specific jobs associated with the HR job titles, information on the average number of minutes spent in specific process areas and performing specific tasks was also obtained for each HR job title from the work history questionnaire. The combination of task, process area, and HR job title was used to assign job codes to portions of times in different process areas for each HR job title; the job codes were based on the job codes in the exposure survey databases. A specific job code was assigned whenever feasible; however, when workers identified multiple work locations or tasks, a job group code was assigned that covered the locations and tasks performed by the worker. For jobs in the production areas of the plant, grouping was based on combining jobs within a process area, co-located jobs, or multiple jobs performed by an individual. For jobs in the non-production areas of the plant, grouping was based on whether a worker in a job spent a greater proportion of time on the plant floor versus in offices away from the plant, or their skills (engineers, electricians, mechanics, etc). The job or job group codes in the JEM are henceforth referred to as exposure codes. A total of 89 exposure codes were identified from the work histories of the study population. An example of assigning exposure codes to the work histories is provided in table 2. The percent time for each exposure code within a HR job title was calculated as shown in table 2 .

Baseline exposures for exposure codes in the JEM. Data from the CFC total and impactor surveys were available to create $\mathrm{BEE}$ for $\mathrm{CFC}$ total, respirable, and submicron particles for the 89 exposure codes. The CFC total BEE for the exposure codes were calculated using the CFC

Table 2. Assignment of exposure codes to work histories: an example of a hypothetical worker's work history.

\begin{tabular}{|c|c|c|c|c|c|c|}
\hline \multirow{2}{*}{$\begin{array}{l}\text { Human resources job title and } \\
\text { start/end date of working period }\end{array}$} & \multicolumn{3}{|c|}{ Process / work area } & \multicolumn{3}{|c|}{ Exposure code } \\
\hline & Area worked & Tasks & Time (min/day) & Code & Time (\%) & Description \\
\hline \multirow[t]{3}{*}{$\begin{array}{l}\text { Induction furnace operator } \\
5 / 15 / 1995-1 / 15 / 1996\end{array}$} & Induction furnace & $\begin{array}{l}\text { 1. Charge furnace } \\
\text { 2. Rub and skim } \\
\text { 3. Pour furnace }\end{array}$ & 371 & $414-50$ & 85 & $\begin{array}{l}\text { Induction furnace } \\
\text { operator }\end{array}$ \\
\hline & Scrap furnace & $\begin{array}{l}\text { 1. Charge furnace } \\
\text { 2. Rub and skim } \\
\text { 3. Pour furnace } \\
\text { 4. Clean tundish }\end{array}$ & 71 & $414-51$ & 15 & Scrap furnace operator \\
\hline & Miscellaneous ${ }^{a}$ & & 38 & $414-50$ & & \\
\hline \multirow[t]{5}{*}{$\begin{array}{l}\text { Pebble plant furnace operator } \\
1 / 15 / 1996-6 / 15 / 1998\end{array}$} & Fluoride furnace & $\begin{array}{l}\text { 1. Probe fume duct } \\
\text { 2. Clean feed tubes } \\
\text { 3. Production work }\end{array}$ & 302 & $110-112$ & 100 & $\begin{array}{l}\text { Fluoride furnace } \\
\text { operator }\end{array}$ \\
\hline & Reduction furnace & $\begin{array}{l}\text { 1. Charge furnace } \\
\text { 2. Change drum } \\
\text { 3. Probe melts } \\
\text { 4. Pour furnace }\end{array}$ & 10 & $110-112$ & & $\begin{array}{l}\text { Reduction furnace } \\
\text { operator }\end{array}$ \\
\hline & $\begin{array}{l}\text { Melts crush-pebble } \\
\text { inspection }\end{array}$ & $\begin{array}{l}\text { 1. Transfer, crush, melt, } \\
\text { clean, and paint } \\
\text { 2. Inspect pebbles } \\
\text { 3. Change discharge drum }\end{array}$ & 63 & $110-112$ & & Patterson mill operator \\
\hline & ABF calciner area & Production work & 77 & $110-112$ & & \\
\hline & Miscellaneous a & & 28 & $110-112$ & & \\
\hline Billet preparation operator & Induction furnace & 1. Billet preparation & 442 & 424 & 100 & Billet preparation \\
\hline 6/15/1998-2/15/1999 & Miscellaneous ${ }^{a}$ & 2. Bıllet grındıng & 38 & 424 & & \\
\hline
\end{tabular}

a Miscellaneous = shoe change room, clean locker room, cafeteria break/lunch 
survey data. The respirable exposures (following the International Organization for Standardization's respirable convention with a $D_{50}$ of $4 \mu \mathrm{m}$ ) were extracted from impactor samples using Simpson's rule approach to estimate the contribution of each impactor stage to the respirable fraction as described in detail by Virji et al (5). The submicron exposures were estimated by summing the stages with particles $<0.93 \mu \mathrm{m}$ (ie, stage 8 and the final filter of the impactor sample). For CFC total beryllium, 52 of the 89 exposure codes in the JEM were assigned the more specific job codes, and the remaining 37 were assigned the job group codes (combined multiple jobs). The impactor survey did not include all the jobs covered by the CFC total data, and only 6 of the 89 exposure codes in the JEM were assigned specific job codes for the respirable or submicron beryllium particles; 71 were assigned the job group codes, and the remaining 12 could not be assigned a job or job group codes. For the 12 missing exposure codes, BEE for the respirable and submicron particles were calculated by multiplying the $\mathrm{CFC}$ total exposure for an exposure code by the ratio of the respirable (or submicron) particles to $\mathrm{CFC}$ total exposure for a process area as described below:

$$
\begin{array}{ll}
B E E_{r / s, e c}=B E E_{t, e c} \times \frac{B E E_{r / s, p a}}{B E E_{t, p a}} & \text { (Equation 1) } \\
\text { Where } & \begin{array}{l}
\text { baseline respirable or submicron particle personal } \\
\text { exposure for an exposure code }
\end{array} \\
B E E_{r / s, e c} & \text { baseline CFC total personal exposure for an expo- } \\
B E E_{t, e c} & \text { sure code } \\
B E E_{r / s, p a} & \text { baseline respirable or submicron particle personal } \\
& \text { exposure for a process area } \\
B E E_{t, p a} & =\begin{array}{l}
\text { baseline CFC total personal exposure for a process } \\
\text { area }
\end{array}
\end{array}
$$

The minimum variance unbiased estimator (MVUE) of the arithmetic mean was calculated for CFC total, respirable, and submicron particles for each exposure code. The arithmetic mean is the desired measure of central tendency for estimating cumulative exposure in chronic disease investigations (16), and the MVUE is the preferred estimator of the arithmetic mean when the data are lognormally distributed (17). The iterative MVUE calculation used estimates of the mean and variance of the log-transformed exposure data, which in turn were obtained using the MLE method to account for data below the LOD. Specifically, the NLMIXED procedure in SAS (SAS Institute, Cary, NC, USA) was used to obtain estimates of the mean and variance of the log-transformed exposure data accounting for the measurements below the LOD as described in detail by Virji et al (5). Furthermore, sampling duration of the impactor samples for some low exposure jobs or job groups was variable and included multi-day or multi-shift samples (range: $2-5$ days/shifts), hence the multi-day/shift samples were weighted by the number of sampling days/shifts in calculating the arithmetic mean.

Development of a job exposure matrix. A JEM was created consisting of 89 rows (exposure codes) representing the job-axis and 6 columns representing the years, from 1994-1999. The cells in the JEM contained the MVUE mean values for CFC total, respirable, and submicron particle beryllium exposures. The HEE for the JEM cells ( $H E E_{\text {particle size,exposure code,year }}$ ) were calculated by applying the temporal factor $\left(T F_{\text {process area, year }}\right)$ to the $\mathrm{BEE}$ of exposure codes $\left(B E E_{\text {particle size, exposure code }}\right)$ in the respective process areas as described in equation 2.

All exposure codes within a process area were weighted by the same temporal factor value.

$$
H E E_{p s, e c, y}=B E E_{p s, e c} \times T F_{p a, y} \quad \text { (Equation 2) }
$$

Where

$\begin{array}{ll}H E E_{p s, e c, y}= & \begin{array}{l}\text { historical } \mathrm{CFC} \text { total, respirable, submicron (particle } \\ \text { size) exposures for exposure codes and year }\end{array} \\ B E E_{p s, e c}=\begin{array}{l}\text { baseline CFC total, respirable, submicron (particle } \\ \text { size) exposures for exposure codes in } 1999\end{array} \\ T F_{p a, y}=\text { fractional annual change for process areas and year }\end{array}$

\section{Generating personal exposure estimates}

Personal exposures were estimated for study participants for each job performed over their work tenure from 1994-1999 to obtain their exposure profile. The HEE from the JEM were combined with individual worker's work history of jobs performed over the study period to obtain their work-tenure exposure profile. This was accomplished through gathering work histories from individuals and assigning exposure codes from the JEM to the HR job titles recorded in the work histories (as described in table 2).

Assigning exposures to individuals' work histories. Individual work histories were linked with exposure estimates $\left(H E E_{p s, e c, y}\right)$ from the JEM to generate historical $\mathrm{CFC}$ total, respirable, and submicron particle beryllium exposure $\left(C_{p s, e c, y}\right)$ profiles for each study participant. Each worker's work history was broken up by calendar year in each job title as shown in table 3. A HR job titlespecific time weighted average beryllium exposure for each calendar year $\left(C_{p s, H R, j, y}\right)$ was calculated by weighting the $C_{p s, e c, y}$ 's assigned to the job title with the fraction 
Table 3. An example of summary respirable beryllium exposure estimates. [HEE=historical exposure estimates; TWA=time-weighted average.]

\begin{tabular}{|c|c|c|c|c|c|c|c|}
\hline $\begin{array}{l}\text { Human resources job title and } \\
\text { start/end date of working period }\end{array}$ & $\begin{array}{l}\text { Exposure } \\
\text { code }\end{array}$ & $\begin{array}{c}\text { Time } \\
\left(\mathrm{f}_{\mathrm{d}}\right)\end{array}$ & $\begin{array}{l}\text { HEE } \\
\left(\mu \mathrm{g} / \mathrm{m}^{3}\right)\end{array}$ & $\begin{array}{l}\text { HR job } \\
\text { exposure }\end{array}$ & Year & Year fraction (fy) & $\begin{array}{l}\text { Year-specific TWA } \\
\text { human resources job }{ }^{b}\end{array}$ \\
\hline Induction furnace operator & $414-50$ & 0.85 & 2.026 & 1.863 & 1995 & $0.63(230 / 365)$ & 1.174 \\
\hline \multirow[t]{3}{*}{ 5/15/1995-1/15/1996 } & $414-51$ & 0.15 & 0.937 & & & & \\
\hline & $414-50$ & 0.85 & $2.026^{c}$ & 1.863 & 1996 & $0.04(15 / 365)$ & 0.075 \\
\hline & $414-51$ & 0.15 & $0.937^{c}$ & & & & \\
\hline \multirow{3}{*}{$\begin{array}{l}\text { Pebble plant furnace operator } \\
1 / 15 / 1996-6 / 15 / 1998\end{array}$} & $110-112$ & 1.00 & $3.981^{d}$ & 3.981 & $1996^{e}$ & $0.96(350 / 365)$ & 3.822 \\
\hline & $110-112$ & 1.00 & 3.981 & 3.981 & 1997 & $1.00(365 / 365)$ & 3.981 \\
\hline & $110-112$ & 1.00 & 2.250 & 2.250 & 1998 & $0.45(166 / 365)$ & 1.013 \\
\hline Billet preparation operator & 424 & 1.00 & 0.188 & 0.188 & 1998 & $0.55(199 / 365)$ & 0.103 \\
\hline 6/15/1998-2/15/1999 & 424 & 1.00 & 0.125 & 0.125 & 1999 & $0.13(46 / 365)$ & 0.016 \\
\hline
\end{tabular}

a Mean HR job exposure by year $=\sum_{j o b} \operatorname{HEE}\left(c_{p s, e c, y}\right) \times \operatorname{Time}\left(f_{d}\right)$

b Year-specific TWA HR job exposure $=f_{y} \times \sum_{i o b} \operatorname{HEE}\left(c_{p s, e c, y}\right) \times \operatorname{Time}\left(f_{d}\right)$

c HEE did not change over time in the process areas in this example, so HEE estimates are the same for different years.

d Highest-ever job exposure.

e Year of the highest-ever job exposure.

${ }^{\mathrm{f}}$ Duration of exposure.

${ }^{g}$ Cumulative exposure $\sum_{\text {year }} f_{y} \sum_{j o b} H E E\left(C_{p s, e c, y}\right) \times$ Time $\left(f_{d}\right)$

Average exposure $=$ cumulative exposure $\div$ duration $=10.184 \mu \mathrm{g} / \mathrm{m}^{3} \times$ year $\div$ 3.76 years $=2.709 \mu \mathrm{g} / \mathrm{m}^{3}$

of day $\left(f_{d}\right)$ associated with the estimate and summing across all the estimates (table 3 ).

Table 3 is an example of a hypothetical worker's entire work history exposure profile for respirable beryllium exposure and is replicated for the CFC total and submicron particle beryllium exposures.

$C_{p s, H R j, y}=\sum_{J o b} C_{p s, e c, y} \times f_{d}$ (Equation 3)

Where

$C_{p s, H R j, y}=$ mean $\mathrm{HR}$ job title (CFC total, respirable or submi-

$C_{p s, e c, y}=$ mean (CFC total, respirable or submicron) exposure $f_{d} \quad=\quad$ fraction of day (work shift) in the calendar year

Creation of summary exposure metrics. Each study participant's work-tenure exposure profiles for the different size beryllium particles (CFC total, respirable, and submicron particles) were summarized for use in epidemiologic analyses (13). A series of summary exposure metrics were created to examine possible relationships of these metrics to biologically plausible exposure fac- tors (particle size and summary exposure metrics) for BeS and CBD, including: simple work-tenure cumulative exposure, work-tenure average exposure, and the highest-ever job exposure.

Cumulative exposure summary metric. The work-tenure cumulative exposure metric $\left(C E_{p s}\right)$ was calculated for each worker by multiplying the HR job title exposure $\left(C_{p s, H R, y}\right)$ by the proportion of time in years $\left(f_{y}\right)$ the job was performed in that calendar year and summing the product across all HR job titles and years as shown in equation 4.

(Equation 4)

Cumulative Exposures $\left(C E_{p s}\right)=\sum_{\text {Year }} \sum_{\text {HRJob }} C_{p s, H R j, y} \times f_{y}$

Average exposure summary metric. The work-tenure average exposure $\left(A V_{p s}\right)$ was calculated by dividing the $C E_{p s}$ by the total duration of employment from the start of their first job post on 1 January 1994 to the date of $\mathrm{BeS}$ or CBD diagnosis or the epidemiologic survey:

(Equation 5)

Average Exposures $\left(A V_{p s}\right)=\frac{C E_{p s}}{\sum f_{y}=(\text { Duration })}$ 
Highest-ever job exposure summary metric. The highestever job exposure summary metric was calculated as a surrogate measure for peak exposure as instrumentation for continuous monitoring of beryllium exposure is currently unavailable to identify peaks. While several definitions of peak exposure will be explored in the future, our initial analyses will be for highest-ever job exposure $\left(C_{p s, e c}\right)$.

An example of the calculations of three of the summary metrics is illustrated in table 3 . All summary exposure metrics calculated for the three beryllium exposure size fractions (CFC total, respirable, and fine particles) were used in the epidemiological exposure-response models as representing different mechanisms for BeS and CBD to investigate their associations with these health outcomes.

\section{Statistical analysis}

All statistical analyses were done in PC-SAS version 9.2 (SAS Institute, Cary, NC, USA). The distributions of exposures were investigated through statistical testing using Shapiro Wilk's test and were also evaluated graphically by plotting histograms and probability plots to determine if transformation of the data was necessary. Analyses of the general area air sampling data were conducted to evaluate changes in air levels over time and across process areas, and temporal factors were developed. Plots of general area air levels versus time were prepared in SigmaPlot 9.01 (Systat Software Inc, San Jose, CA, USA) for the overall data as well as for process areas to observe any trend in air levels over time. Tobit regression models were fit to the log-transformed general area air sampling data for each process area using the LIFEREG procedure in SAS with year or timeperiod grouping as a categorical independent variable and the year 1999 as the reference category. Additionally, the general area samples were not available from the same locations within a process area for every year; hence the Tobit model included a sample location term to account for potential confounding between location and year. Process areas with $\geq 70 \%$ of measurements below the LOD were not used in time trend analyses as the validity of the estimates from Tobit regression for $>70 \%$ censored data is not known (15); these processes were evaluated using the MLE mean method. The parameter estimates for the year variable from the model $\left(\beta_{1994}-\beta_{1998}\right)$ are exponentiated to obtain the temporal factors: measures of the change in exposure levels for any given year (or group of years) relative to exposure levels in 1999. The Tobit models were also run with the number of years prior to 1999 (baseline year) as a continuous independent variable, overall and by process areas to obtain a measure of mean annual percent decline in exposure, as calculated in equation 6 as (18):

(Equation 6)

Mean Annual \% Decline $=100 \times\left[\exp \left(\beta_{1}\right)-1\right]$

Descriptive/summary statistics were calculated for all the summary exposure metrics for the study population. Scatter plots and both Spearman $\left(r_{s}\right)$ and Pearson $\left(r_{p}\right)$ correlation coefficients were calculated to evaluate the associations among the three exposure measures (CFC total, respirable, and submicron particles) and among the three summary exposure metrics (cumulative, average, and highest exposures).

\section{Results}

A large fraction (39.5\%) of the general area data were below the LOD, and ranged from $17-100 \%$ for the different process areas, and $4-100 \%$ for the different years and process areas (table 1). The number of general area air sample varied by process areas ranging from 11-13 478 measurements, collected from varying locations in each process area.

\section{Time trend analysis}

The general area air samples showed an overall declining trend in exposure over time, but the trend was variable by process areas (data not shown). Tobit regression model with the number of years prior to 1999 (baseline year) as a continuous independent variable and correcting for sampler location showed a decline in exposure of $18.2 \%$ per year over the six-year period from 1994 1999. The decline in exposure remained unchanged $(18.2 \%$ per year) when the general area air samples were limited to production area air samples only $(\mathrm{N}=72$ 316 and $\mathrm{LOD}=36.9 \%$ ). The crude model (not including sampler location) showed a $21.5 \%$ and $22.5 \%$ per year decline in exposure for the overall data and productionareas-only data, respectively.

The number of general area samples collected in a year as a fraction of the total number of general area samples collected over the six years (1994-1999) ranged from a minimum of $10.8 \%$ in 1999 to a maximum of $25.6 \%$ in 1995 . Of the 24 process areas from which general area air samples were available, time trend analyses could not be conducted on 10 process areas due to a large fraction $(\geq 70 \%)$ of the measurements being below the LOD for most years and/or small sample size $(\mathrm{N}<20)$. Most of these process areas were in the non- 
production areas of the plant, and the mean air levels within these processes (obtained using MLE methods) were similar from year to year. Of the remaining process areas, time trends were observed in nine process areas including: wet plant, pebbles plant, oxide, powder metal products, atomizer, whiting furnace, old cast shop \& billet preparation, old strip mill, and scrap furnace areas. Time trends were not observed in five areas including: new cast shop, quality assessment/quality control/ research and development, resource recovery, shipping and receiving, and janitorial services.

Overall, the temporal factors ranged from 1-4.6, and the changes in exposure over time were generally stepwise and often corresponded to changes in the workplace (eg, implementation of controls or process enclosures) $(19,20)$.

\section{Summary of exposure indices for the study population}

A total of nine exposure indices were generated for the study population resulting from three measures of exposure (CFC total, respirable, and submicron particles) and three summary exposure metrics (table 4). Figure 2 provides more details on the distribution of the summary exposure metrics for respirable beryllium exposure. The histogram of cumulative exposure suggests a lognormal distribution, while the histograms for average and highest exposure suggest possible bimodal distribution, with a long right tail. A majority of the workers were in the lower end of the exposure distributions. Similar results were obtained for the CFC total and submicron exposures.

\section{Correlations among exposure measures and summary exposure metrics}

Correlations between CFC total and respirable or submicron particles for the summary metrics (cumulative, average, and highest-ever) were moderate $\left(\mathrm{r}_{\mathrm{p}}\right.$ range: $0.37-0.54$ ) likely due to the right skew of the summary metrics (partially shown in figure 3 ). However, the rank order of the summary metrics for study participants showed high consistency between the pairs of exposure measures ( $\mathrm{r}_{\mathrm{s}}$ range: $\left.0.86-0.94\right)$. The correlations between respirable and submicron particles for the summary metrics were high (range: 0.94-0.98) for both Pearson and Spearman correlations (data not shown). Correlations among summary exposure metrics for respirable and CFC total beryllium exposure showed high Pearson and Spearman correlations (range 0.80-0.91) (figure 4). The correlations among the summary metrics for submicron particles followed a similar pattern to those of respirable and CFC total exposures (data not shown). Duration of exposure was moderately correlated with cumulative exposure $\left(\mathrm{r}_{\mathrm{p}}=0.65\right)$ and poorly correlated with average or highest-ever exposure $\left(\mathrm{r}_{\mathrm{p}}=0.32-0.45\right)$ (data not shown).

Table 4. Summary of personal exposure summary metrics. [CFC=closed face cassette]

\begin{tabular}{|c|c|c|c|c|c|c|c|c|c|}
\hline \multirow[t]{2}{*}{ Summary exposure metric } & \multicolumn{3}{|c|}{ CFC total exposure } & \multicolumn{3}{|c|}{ Respirable exposure } & \multicolumn{3}{|c|}{ Submicron exposure } \\
\hline & Mean & Median & Range & Mean & Median & Range & Mean & Median & Range \\
\hline Duration (years) & 1.9 & 1.7 & $0.02-6.1$ & & & & & & \\
\hline Cumulative exposure ( $\mu \mathrm{g} / \mathrm{m}^{3}$-year) & 2.11 & 0.64 & $0.001-34.44$ & 1.46 & 0.52 & $0.001-15.54$ & 0.37 & 0.11 & $0.001-5.63$ \\
\hline Average exposure $\left(\mu \mathrm{g} / \mathrm{m}^{3}\right)$ & 0.88 & 0.61 & $0.01-16.26$ & 0.61 & 0.43 & $0.01-3.56$ & 0.15 & 0.09 & $0.001-1.31$ \\
\hline Highest-ever exposure $\left(\mu \mathrm{g} / \mathrm{m}^{3}\right)$ & 1.64 & 0.93 & $0.01-17.54$ & 1.02 & 0.87 & $0.01-5.54$ & 0.26 & 0.15 & $0.001-2.08$ \\
\hline
\end{tabular}
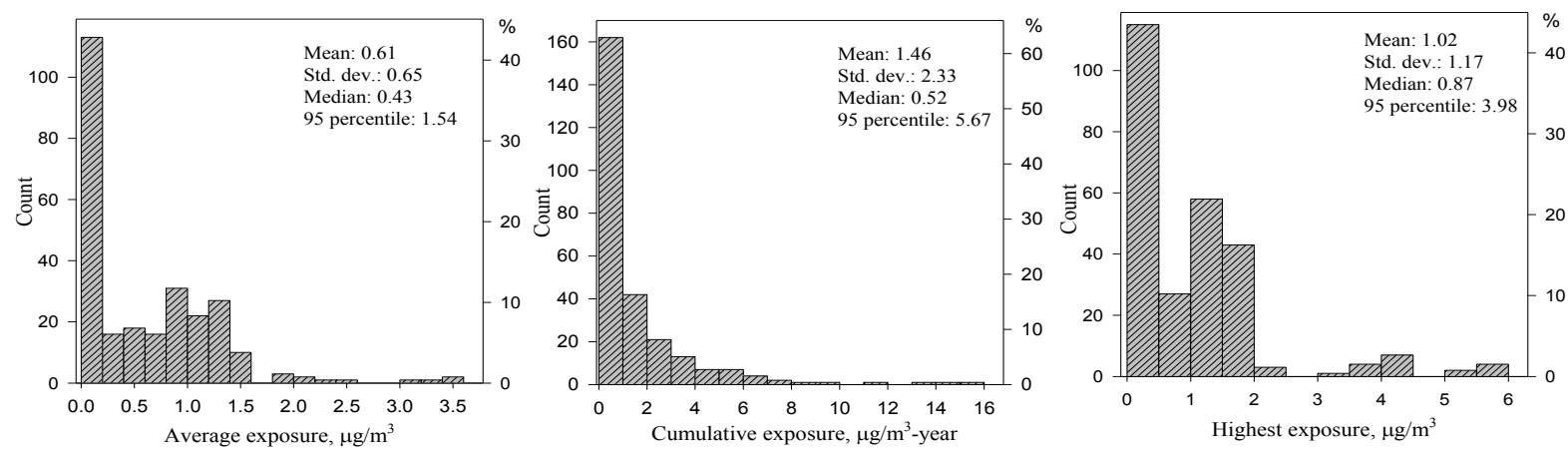

Figure 2. Summary statistics and exposure distributions of the study participants for respirable summary exposure metrics (average, cumulative and highest-ever job) 


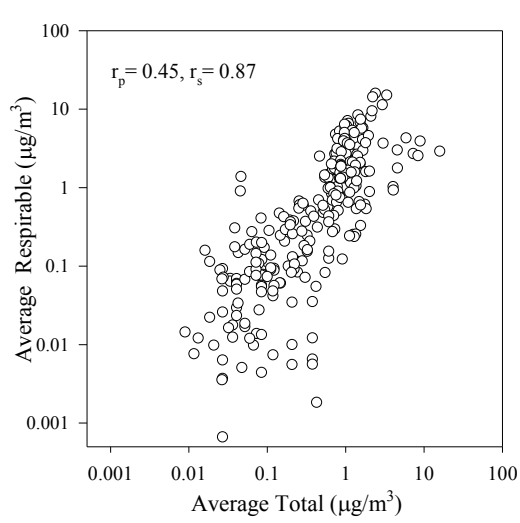

(a) Average exposure

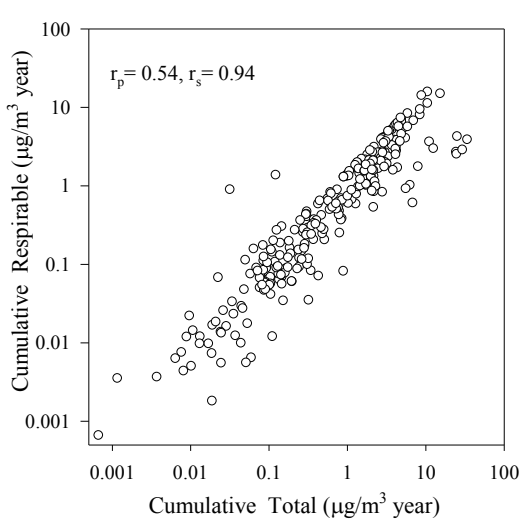

(b) Cumulative exposure

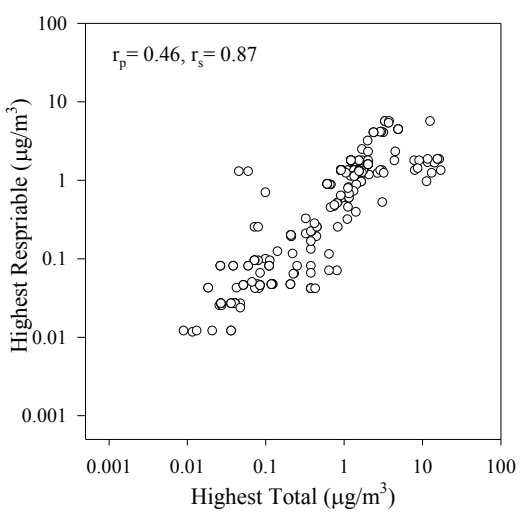

(c) Highest exposure

Figure 3. Correlations between respirable and CFC (closed face cassette) total exposure indices for average (a), cumulative (b) and highest-ever job (c) summary exposure metrics. [ $r_{p}=P$ earson correlation; $r_{s}=$ Spearman correlation.]

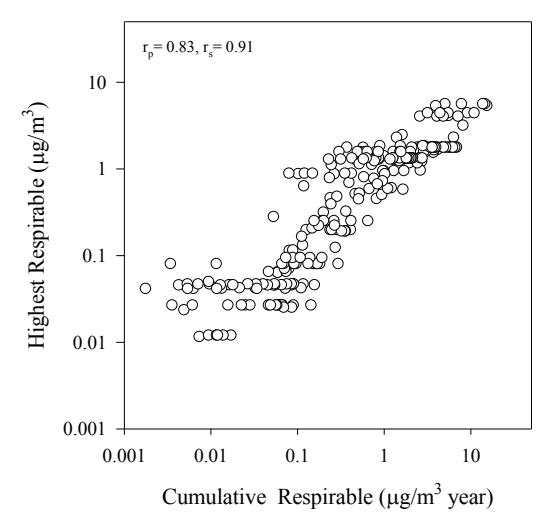

(a) Respirable exposure

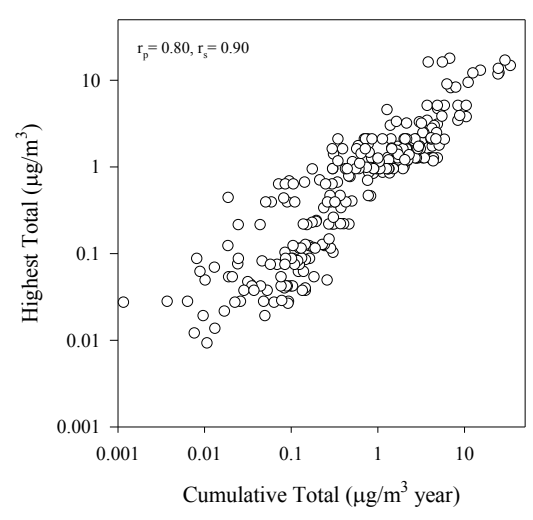

(b) Total exposure
Figure 4. Correlations between cumulative and highest-ever job summary exposure metrics for respirable (a) and CFC (closed face cassette) total (b) exposure estimates. [ $r_{p}=$ Pearson correlation; $r_{\mathrm{s}}=$ Spearman correlation.]

\section{Discussion}

Previous epidemiologic studies of BeS and CBD suggest that exposure-dependent risks do exist, however exposure-response relationships have been inconsistent, likely due, in part, to exposure misclassification. Most studies of BeS and CBD have used qualitative exposure surrogates such as job or process, or quantitative surrogates of personal beryllium exposure such as the daily weighted average, breathing zone, or general area as the exposure indicator in epidemiologic analyses. In these studies, older sampling records of breathing zone, general area, and daily weighted average have been used to estimate participants' historical exposures. However, these metrics are poorly correlated with personal respirable $(\mathrm{r}=0.33)$ or $\mathrm{CFC}$ total $(\mathrm{r}=0.49)$ beryllium exposure metrics (21). It was recognized that the epidemiologic studies conducted to date have not fully incorporated potentially important exposure characteristics such as particle size and solubility in estimating personal historical exposures for study subjects, which may in part explain the inconsistent exposure-response results (2).

In this paper, we begin addressing these challenges in exposure assessment by generating historical estimates of personal exposure that take into consideration particle size distribution of the beryllium aerosol in this workplace. This study benefitted from the large and comprehensive datasets of personal exposures to estimate the baseline exposure for a JEM and the equally large and comprehensive general area air sampling dataset to estimate changes in air levels over time. These datasets were used together to develop the historical estimates of personal exposure to CFC total, respirable, and submicron beryllium particles. This is the first step in a strategy to develop biologically relevant exposure metrics for $\mathrm{BeS}$ and $\mathrm{CBD}$, that also includes other potentially relevant exposure factors such as skin exposure, particle solubility in biological fluids, and relevant summary exposure metrics such as peak exposure. 


\section{Time trend analysis}

One of the principal assumptions of retrospective exposure assessment is that exposure levels have changed over time as a result of process changes, introduction of ventilation controls and enclosures, and changes in regulations among other factors (22). Therefore, contemporary exposure estimates need to be adjusted based on these factors to estimate past exposures. Studies in a number of industrial settings (23-26) provide evidence of changes in exposure levels over time. For example, Creely et al (22) reviewed the published literature on temporal changes in inhalation exposure and showed a range of $-19 \%$ to $>4 \%$ change in annual exposures for aerosols, a majority of the studies showing a decline in exposure levels over time. However, information about changes in the working environment, process conditions, or other factors that may have influenced the change in exposure over time was lacking in many of the studies reviewed. In this study, we observed an overall $18 \%$ annual decline in general area air levels, which is within the range reported in the literature.

\section{Summary exposure metrics}

Summarizing time-varying historical exposure profiles into summary exposure metrics for use in epidemiologic studies involves implicit or explicit assumptions about the relationship between exposure and disease and the time patterns of the effects of exposure $(27,28)$. Cumulative exposure is the most common exposure index used in epidemiologic studies of chronic effects. Cumulative exposure is particularly relevant when it is proportional to dose at the target tissue and the dose is proportional to the risk of disease, as in the case of exposure to dusts and a number of lung diseases (16, 29). Thus in the case of CBD, cumulative exposure may be the relevant summary metric as an adequate lung burden is likely needed for the development of granulomas. However, cumulative exposure may not be a valid exposure index when the relationship between external exposure and the biologically relevant dose is not a linear function of exposure, for example in disease processes involving sensitization $(28,30)$. The association between $\mathrm{BeS}$ and exposure is hypothesized to be non-linear, requiring alternative summary exposure metrics such as peak exposure and involving solubility. The highest-job-worked exposure metric, representing the highest-intensity job a worker held (a relative peak), has been used as a surrogate for peak exposure in a number of industries including the beryllium industry using the daily weighted average data $(31,32)$. In the present study, high correlations were observed among the various summary exposure metrics including cumulative exposure and average and highest job exposure, which may limit their ability to distinguish difference among the metrics in epidemiologic analysis. The high correlation may in part be due to the similarity of the average and highest-ever job exposure, combined with the relatively short work tenure (average $<2$ years) for most study participants. Nevertheless, differences in the exposure-response relation have been observed even when the summary exposure metrics are highly correlated $(\mathrm{r}=0.68-0.88)(33)$.

\section{Implications for epidemiology}

To decipher subtle associations between moderate levels of exposure and health risks, epidemiologic studies require precise and biologically valid estimates of exposure and analytical models that reflect the biological mechanisms. Ideally, the chosen exposure metric is biologically relevant $(27,34)$; however, in practice, the exposure metric is often selected based on the type of exposure data available. For example, most epidemiologic studies of $\mathrm{BeS}$ and $\mathrm{CBD}$ have used the available historical data such as the daily weighted average. Choosing a surrogate exposure metric (eg, daily weighted average) in place of a more proximal indicator (eg, respirable or inhalable-sized soluble or poorly soluble particles) can lead to attenuation of observed exposure-response relationships (35). For future epidemiologic studies of $\mathrm{BeS}$ and $\mathrm{CBD}$, biologically meaningful exposure metrics can be generated by taking into consideration: (i) particle size distribution (mass or number) for different job categories; (ii) probability of deposition in the respiratory tract; (iii) solubility of different forms of beryllium; and (iv) the time course of exposure. The biological mechanisms are hypothesized to be different for BeS and CBD; hence, different summary exposure metrics are likely needed. For CBD, a cumulative, respirable exposure-type metric that takes into consideration the particle solubility may be the most relevant metric. For BeS, a short-duration or peak-inhalation exposure metric and/or a skin exposure metric that take into consideration particle solubility may be the more relevant exposure metrics. A better understanding of the exposure characteristics that are associated with $\mathrm{BeS}$ and $\mathrm{CBD}$ will help in devising more effective prevention strategies.

\section{Limitations}

As with any study involving the use of historical information and data, a major limitation is the availability and quality of those data. The impactor and cassette samples collected during two sampling campaigns in 1999 had several limitations discussed in detail by Virji et al (5) including: short sampling campaigns, impactor sampling focused on small particles only, and lack of 
contextual information during exposure monitoring. A large fraction of the general area air sampling measurements were below the LOD and the percentage varied among process areas. While we used MLE methods to account for the left censored data in estimating model parameters, robust methods are currently unavailable to model severely censored data of small sample size $(>70 \%$ below the LOD for $\mathrm{N}<20$ ). Moreover, time trends could not be modeled for some process areas due to the small number of samples collected from those areas and/or a large fraction of the measurements below the LOD. The exposure reconstruction approach made the assumption that time trends in general area air sampling data represented the time trends in personal exposures. Finally, the quality of work histories varied from having detailed information on tasks and locations that facilitated the assignment of the more specific exposure code, to little details on tasks and locations resulting in the assignment of the broader job-group-based exposure codes. These limitations are common to most studies relying on historical and/or self-reported information.

In this paper, we begin addressing challenges in exposure assessment that may have hampered previous epidemiologic studies from observing consistent exposure-response relationships. Historical estimates of personal exposure to CFC total, respirable, and submicron particles beryllium were generated by combining BEE with temporal factors for the study population. This study benefitted from large and comprehensive datasets of personal exposures to estimate the baseline exposure for the JEM, general area air sampling dataset to estimate changes in exposure over time, and short work tenure to minimize uncertainty in the time between first exposure and onset of $\mathrm{BeS}$ or $\mathrm{CBD}$. A range of summary exposure metrics were calculated from the individual's exposure profile including cumulative, average, and highest exposures. The ultimate objective is elucidating a quantitative exposure-response relationship for $\mathrm{BeS}$ and CBD. The JEM estimates form the basis upon which biological exposure metrics can be generated that incorporate additional exposure factors such as particle solubility, skin exposure as an alternative route for sensitization, and multiple summary metrics that explore different patterns of exposure over time.

\section{Ethics}

Michael S Kent is employed by Materion Brush Inc, the owner of the beryllium manufacturing facility described in this report.

\section{Acknowledgements}

The authors thank Dr Paul Henneberger and Brent Doney for their critical review of this manuscript. We also thank Nicole Edwards and Brian Tift for data management and Dr David Deubner for useful discussion of this work.

\section{References}

1. Kreiss K, Day GA, Schuler CR. Beryllium: A Modern Industrial Hazard. Public Health. 2007;28:259-77. doi:10.1146/annurev.publhealth.28.021406.144011.

2. National Academy of Science (NAS). Managing health effects of beryllium exposure. Washington, DC: National Academies Press; 2008.

3. Kreiss K, Mroz MM, Zhen B, Wiedemann H, Barna B. Risks of beryllium disease related to work processes at a metal, alloy, and oxide production plant. Occup Environ Med. 1997;54:605-12. doi:10.1136/oem.54.8.605.

4. Rosenman K, Hertzberg V, Rice C, Reilly MJ, Aronchick J, Parker JE, et al. Chronic beryllium disease and sensitization at a beryllium processing facility. Environ Health Perspect. 2005;113:1366-72. doi:10.1289/ehp.7845.

5. Virji MA, Stefaniak AB, Day GA, Stanton ML, Kent MS, Kreiss K, et al. Characteristics of beryllium exposure to small particles at a beryllium production facility. Ann Occup Hyg. 2011; 55 (1) 70-85. doi:10.1093/annhyg/meq055.

6. Kent MS, Robins TG, Madl AK. Is total mass or mass of alveolar-deposited airborne particles of beryllium a better predictor of the prevalence of disease? A preliminary study of a beryllium processing facility. Appl Occup Environ Hyg. 2001;16:539-58. doi:10.1080/104732201750169633.

7. Henneberger PK, Cumro D, Deubner DD, Kent MS, McCawley M, Kreiss K. Beryllium sensitization and disease among long-term and short-term workers in a beryllium ceramics plant. Int Arch Occup Environ Health. 2001;74:16776. doi:10.1007/s004200100237.

8. Kreiss K, Mroz MM, Newman LS, Martyny J, Zhen B. Machining risk of beryllium disease and sensitization with median exposures below $2 \mathrm{mg} / \mathrm{m}^{3}$. Am J Ind Med. 1996;30:1625. doi:10.1002/(SICI)1097-0274(199607)30:1<16::AIDAJIM3>3.0.CO;2-Q.

9. Stefaniak AB, Day GA, Hoover MD, Breysse PN, Scripsick RC. Differences in dissolution behavior in a phagolysosomal simulant fluid for single-component and multi-component materials associated with beryllium sensitization and chronic beryllium disease. Toxicol In Vitro. 2006;20:82-95. doi:10.1016/j.tiv.2005.06.031.

10. Stange AW, Hilmas DE, Furman FJ, Gatliffe TR. Beryllium sensitization and chronic beryllium disease at a former nuclear 
weapons facility. Appl Occup Environ Hyg. 2001;16:405-17. doi:10.1080/104732201750154305.

11. Viet S, Torma-Krajewski J, Rogers J. Chronic beryllium disease and beryllium sensitization at Rocky Flats: a case-control study. Am Ind Hyg Assoc J. 2000;61:244-54. doi:10.1202/0002-8894(2000)061<0244:CBDABS $>2.0$. $\mathrm{CO} ; 2$.

12. Kelleher PC, Martyny JW, Mroz MM, Maier LA, Ruttenber JA, Young DA, et al Beryllium particulate exposure and disease relations in a beryllium machining plant. J Occup Environ Med. 2001;43:238-49. doi:10.1097/00043764200103000-00012.

13. Schuler CR, Virji MA, Stanton ML, Stefaniak AB, Day GA, Park JY, et al. Sensitization and chronic beryllium disease at a primary manufacturing facility, part 3: exposure-response among short-term workers. Scand J Work Environ Health. 2012;38(3):270-281. doi:10.5271/sjweh3192.

14. Deubner DC, Kelsh M, Shum M, Maier L, Kent MS, Lau E. Beryllium sensitization, chronic beryllium disease, and exposure at a beryllium mining and extraction facility. Appl Occup Environ Hyg. 2001;16:579-92. doi:10.1080/104732201750169697.

15. Lubin JH, Colt JS, Camann D, Davis S, Cerhan JR, Severson RK, et al Epidemiologic evaluation of measurement data in the presence of detection limits. Environ Health Perspect. 2004;112:1691-6. doi:10.1289/ehp.7199.

16. Smith TJ. Occupational exposure and dose over time: limitations of cumulative exposure. Am J Ind Med. 1992;21:35-51. doi:10.1002/ajim.4700210107.

17. Mulhausen JR, Damiano J. A strategy for assessing and managing occupational exposures. Fairfax: American Industrial Hygiene Association Press; 1998.

18. Symanski E, Kupper LL, Rappaport SM. Comprehensive evaluation of long-term trends in occupational exposure: Part 1. Description of the database. Occup Environ Med. 1998;55:300-9. doi:10.1136/oem.55.5.300.

19. Park JY, Virji MA, Stefaniak AB, Stanton ML, Day GA, Kent MS, et al. Sensitization and chronic beryllium disease at a primary manufacturing facility, part 2: validation of historical exposures. Scand J Work Environ Health. 2012;38(3):259 263. doi:10.5271/sjweh.3187.

20. Bailey RL, Thomas CA, Deubner DC, Kent MS, Kreiss K, Schuler CR. Evaluation of a preventive program to reduce sensitization at a beryllium metal, oxide, and alloy production plant. J Occup Environ Med. 2010;52:505-12. doi:10.1097/ JOM.0b013e3181d6c338.

21. Donaldson HM, Stringer WT. Beryllium sampling methods. Am Ind Hyg Assoc J. 1980;41:85-90. doi:10.1080/15298668091424410.

22. Creely K, Cowie H, Van Tongeren M, Kromhout H, Tickner J, Cherrie J. Trends in inhalation exposure a review of the data in the published scientific literature. Ann Occup Hyg.
2007;51:665-78. doi:10.1093/annhyg/mem050.

23. Burstyn I, Kromhout H. Trends in inhalation exposure to hydrocarbons among commercial painters in The Netherlands. Scand J Work Environ Health. 2002;28(6):429-38.

24. Van Tongeren MJA, Kromhout H, Gardiner K. Trends in levels of inhalable dust exposure, exceedance and overexposure in the European carbon black manufacturing industry. Ann Occup Hyg. 2000;44:271-80.

25. Vermeulen R, De Hartog J, Swuste P, Kromhout H. Trends in exposure to inhalable particulate and dermal contamination in the rubber manufacturing industry: effectiveness of control measures implemented over a nine-year period. Ann Occup Hyg. 2000;44:343-54.

26. Symanski E, Kupper LL, Kromhout H, Rappaport SM. An investigation of systematic changes in occupational exposure. Am Ind Hyg Assoc J. 1996;57:724-34. doi:10.1080/15428119691014585.

27. Kriebel D, Checkoway H, Pearce N. Exposure and dose modelling in occupational epidemiology. Occup Environ Med. 2007;64:492-8. doi:10.1136/oem.2006.030031.

28. Smith TJ, Kriebel D. A Biologic Approach to Environmental Assessment and Epidemiology. New York: Oxford University Press; 2010. doi:10.1093/acprof:o so/9780195141566.001.0001.

29. Checkoway H, Pearce N, Kriebel D. Research methods in occupational epidemiology. New York: Oxford University Press; 2004. doi:10.1093/acprof:oso/9780195092424.001.0001.

30. Rappaport SM. Assessment of long-term exposures to toxic substances in air. Ann Occup Hyg. 1991;35:61-122. doi:10.1093/annhyg/35.1.61.

31. Checkoway $\mathrm{H}$, Rice $\mathrm{CH}$. Time weighted averages, peaks, and other indices of exposure in occupational epidemiology. Am J Ind Med. 1992;21:25-33. doi:10.1002/ajim.4700210106.

32. Sanderson WT, Ward EM, Steenland K, Petersen MR. Lung cancer case-control study of beryllium workers. Am J Ind Med. 2001;39:133-44. doi:10.1002/10970274(200102)39:2<133::AID-AJIM1001>3.0.CO;2-7.

33. Friesen MC, Davies HW, Teschke K, Ostry AS, Hertzman C, Demers PA. Impact of the specificity of the exposure metric on exposure-response relationships. Epidemiology. 2007; 18:88-94. doi:10.1097/01.ede.0000249558.18960.6b.

34. Loomis D, Salvan A, Kromhout H, Kriebel D. Selecting indices of occupational exposure for epidemiologic studies. Occup Hyg. 1999;5:73-91.

35. Armstrong BG. Effect of measurement error on epidemiological studies of environmental and occupational exposures. Occup Environ Med. 1998;55:651-6. doi:10.1136/oem.55.10.651.

Received for publication: 1 April 2011 